\title{
PENGARUH WAKAF PRODUKTIF TERHADAP PENINGKATAN EKONOMI PESANTREN DARUNNAJAH JAKARTA
}

\author{
Nufzatutsaniah ${ }^{1)}$ \\ 1) dosen universitas pamulang, email : nufzatutsaniah@gmail.com
}

\section{ARTICLES}

INFORMATION

ABSTRACT

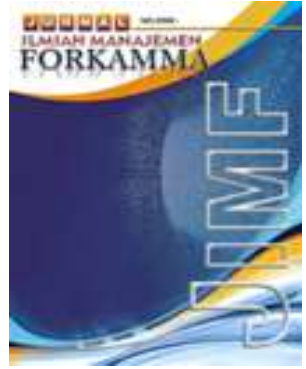

\section{JURNAL ILMIAH MANAJEMEN FORKAMMA}

\author{
Vol.1, No.3, Mei 2018 \\ Halaman : 72-84 \\ (c) LPPM \& FORKAMMA
}

Prodi Magister Manajemen

UNVERSITAS PAMULANG

ISSN (online) : 2599-171X

ISSN (print) : :2598-9545

\section{Keyword :}

wakaf produktif, ekonomi, pesantren.

JEL. classification :

C33, G20, G23, N65

\section{Contact Author : \\ PRODI \\ MAGISTER MANAJEMEN \& FORKAMMA UNPAM \\ JL.Surya Kencana No.1 Pamulang \\ Tangerang Selatan - Banten \\ Telp. (021) 7412566, Fax (021) 7412491 \\ Email : \\ jurnalforkamma.unpam@gmail.com}

Tujuan penelitian ini untuk mengetahui seberapa besar pengaruh kualitas produk dan Pesantren merupakan suatu lembaga pendidikan agama Islam yang tumbuh serta diakui oleh masyarakat sekitar. Kebanyakan dari pesantren berdiri diatas tanah wakaf, yang didalamnya dibangun sarana dan prasarana untuk dapat melaksanakan kegiatan belajarmengajar dengan baik. Salah satu pesantren yang berdiri diatas tanah wakaf adalah Pesantren Darunnajah Jakarta, yang didirikan oleh K.H Abdul Manaf Mukhayar pada tahun 1960. Untuk mendapatkan mutu pendidikan yang berkualitas, maka Pesantren Darunnajah menggali dana dari pesantren sendiri untuk lebih mandiri yang memanfaatkan harta benda wakaf untuk dapat dikelola supaya menjadi produktif. Suatu wakaf dikatakan produktif apabila wakaf tersebut menghasilkan output berupa barang atau jasa. Oleh karena itu dibangunlah unit-unit usaha yang dikelola sendiri oleh pihak Yayasan Darunnajah yang hasilnya untuk kelangsungan kegiatan belajar mengajar di lingkungan Pondok Pesantren Darunnajah dan membantu masyarakat sekitar yang kurang mampu.

Pesantren is an institution of Islamic religious education that grows and is recognized by the community. Most of the pesantren stand on waqaf land in which built facilities and infrastructure to be able to carry out theaching and learning activities well. One of the pesantren standing on waqaf land is pesantren darunnajah Jakarta, founded by KH. Abdul Manaf Mukhayar in 1960. To get the quality of quality education, then pesantren darunnajah dug funds from their own pesantren to be more independent which utilize waqaf property to be managed to be productive. A waqaf is said to be productive if the waqaf produces output in the form of goods and services. Therefore the business units are built self-managed by the foundation darunnajah which results for the continuity of teaching and learning activities in pesantren darunnajah cottage and help the community around the less able. 


\section{A. Pendahuluan}

Sejarah pengelolaan wakaf di Indonesia ini telah mengalami beberapa perkembangan. Paling tidak ada tiga periode besar pengelolaan wakaf di Indonesia, diantaranya : (1) Periode tradisional, dalam periode ini wakaf masih ditempatkan sebagai ajaran yang murni dimasukkan dalam kategori ibadah mahdhah (pokok) yaitu kebanyakan benda wakaf diperuntukan untuk kepentingan pembangunan fisik, seperti masjid, mushala, sekolah pondok pesantren, rumah yatim piatu, makam, yayasan dan lain sebagainya. Sehingga keberadaan wakaf di Indonesia belum memberikan kontribusi sosial yang lebih luas karena hanya untuk kepentingan yang bersifat konsumtif. (2) Periode semi-profesional, dalam periode ini masa dimana pengelolaan wakaf secara umum sama dengan periode tradisional, namun pada masa ini sudah mulai dikembangkan pola pemberdayaan wakaf secara produktif. Sebagai contoh adalah pembangunan masjid-masjid yang letaknya strategis dengan menambah bangunan gedung untuk pertemuan, pernikahan, seminar dan acara lainnya seperti masjid Sunda Kelapa, masjid Pondok Indah, masjid at-Taqwa Pasar Minggu dan lain sebagainya. (3) Periode pengelolaan wakaf secara profesional ditandai dengan pemberdayaan potensi masyarakat secara produktif.

Keprofesionalan yang dilakukan meliputi aspek : manajemen, SDM kenazhiran, pola kemitraan usaha yang berdasarkan asas transparansi. Semangat pemberdayaan potensi wakaf secara profesional produktif tersebut semata-mata untuk kepentingan kesejahteraan umat. ( Achmad Djunaidi dan Thobieb Al-Asyhar, 2006 : v-vii)

Salah satu peruntukan wakaf dibangun untuk bidang pendidikan, yaitu Pesantren yang merupakan lembaga pendidikan Islam tertua yang telah berfungsi sebagai salah satu benteng pertahanan umat Islam, pusat dakwah dan pusat pengembangan masyarakat muslim di Indonesia. Kekhususan pesantren dibandingkan dengan lembagalembaga pendidikan lainya adalah para santri yang tinggal bersama kiai mereka dalam suatu komplek tertentu yang mandiri, sehingga dapat menumbuhkan ciri-ciri khas pesantren, seperti : (1) Adanya hubungan yang akrab antara santri dan kiai, (2) Santri taat dan patuh kepada kiainya, (3) Para santri hidup secara mandiri dan sederhana, (4) Adanya semangat gotong royong dalam suasana penuh persaudaraan, (5) Para santri tertarik hidup berdisiplin.

Agar dapat melaksanakan tugas mendidik dengan baik biasanya sebuah pesantren memiliki sarana fisik yang minimal terdiri dari sarana dasar, yaitu masjid atau langgar sebagai pusat kegiatan, rumah untuk tempat tinggal kyai dan keluarganya, pondok tempat tinggal untuk para santri dan ruangan belajar mengajar. (Abdul Aziz Dahlan, 2002 : 99-100).

Kontribusi pesantren untuk umat atau masyarakat sangat berpengaruh untuk mensejahterakan umat baik dibidang ekonomi, pendidikan dan bidang sosial lain. Salah contoh pondok pesantren di Indonesia yang telah dapat membantu kepentingan umum dalam rangka ikut mensejahterakan umat yang lebih luas, yaitu Pondok Pesantren Modern Darussalam Gontor Ponorogo Jawa Timur. Tanah wakaf yang dimiliki oleh Pondok Pesantren Modern Darussalam Gontor Ponorogo Jawa Timur mampu meningkatkan eksistensi. Yayasan badan wakaf Pondok Modern Gontor memiliki tanah wakaf tersebar di Jawa Timur, Seperti Ngawi, Madiun, Ponorogo, Nganjuk, Kediri, Jombang dan Trenggalek.

Tanah wakaf tersebut sebagian besar dimanfaatkan untuk pertanian dan sebagian kecil untuk perkebunan seperti yang ada di Trenggalek seluas $2.031 \mathrm{Ha}$. Hasil produksi sawah dan perkebunan tersebut sebagian besar dipergunakan untuk kepentingan produktif, bukan untuk kepentingan konsumtif dan memelihara eksistensi pondok dan pengembangan selanjutnya. Sebagian pusat kegiatan, yayasan wakaf tersebut terletak di Desa Gontor merupakan kampus seluas $3 \mathrm{Ha}$, yang terdiri dari bangunan masjid, dua unit asrama santri, sebelas gedung untuk belajar dan sebelas gedung yang lain seperti untuk perpustakaan, koperasi santri, dapur, kafetaria, perumahan dasar dan balai kesehatan. 
Sebagian hasil dari tanah wakaf untuk pemeliharaan pendidikan yang terdiri dari : (1) KMI (Kulliyatul Muallimin al-Islamiyah) di Gontor, (2) KMl khusus putri di Mantingan Ngawi (Kulliyatul Muallimin al-Islamiyah) khusus putri di Mantingan Ngawi, (3) IPD (Insistut Pendidikan Darussalam) sebagai perguruan tinggi di Gontor, (4) PLMPM (Pusat Latihan Manajemen dan Pengembangan Masyarakat) di Mantingan Ngawi.

Manfaat Pondok Pesantren Modern Darussalam Gontor Ponorogo Jawa Timur tidak bisa dilihat dari satu aspek kehidupan saja, tetapi hendaknya juga dilihat dari beberapa aspek kehidupan. Salah satu sumbangan pondok modern ke masyarakat Desa Gontor dalam pembangunan fisik antara lain : (1) Balai Desa Gontor, (2) Listrik untuk jalan-jalan desa, (3) Pompa air untuk sawah desa dengan mesin pembuat lubang dari pondok, (4) Fasilitas lapangan sepak bola dan lapangan bola volly, (5) Sebagian tanah untuk kepolisian Kecamatan Mlarak, (6) Saluran air (kanal) sebelah barat pondok. (Abdul Aziz Dahlan, 2002 : 77-78).

Karena ada kontribusi pesantren dalam mensejahterakan umat baik dalam bidang sosial, ekonomi dan pendidikan, maka umat tertarik untuk mewakafkan sebagian harta yang dimilikinya. Contohnya : seorang wakif Dr. Djojodarmo di Desa Trirenggo Kabupaten Bantul, yang mewakafkan tanahnya seluas $4.218 \mathrm{M}^{2}$, dengan ikrar wakafnya untuk digunakan memajukan masyarakat Islam, ternyata tanah wakaf tersebut sekarang dapat digunakan untuk sarana pendidikan, sarana kesehatan dan lain-lain. ((Abdul Aziz Dahlan, $2002: 78)$.

Akan tetapi dalam perkembangannya wakaf di lingkungan pesantren masih banyak mengalami problem dalam pengelolaan dan pengembangan wakaf. Adapun masalah yang dihadapi adalah : (1) Minimnya pemahaman umat muslim mengenai wakaf itu sendiri, (2) Nazhir atau pengelola wakaf yang bersifat tradisional dan konsumtif, (3) Lemahnya pemegang otoritas, (4) Pengaruh krisis ekonomi dan politik dalam negeri. (Abdul Aziz Dahlan, 2002 : 52-58).

Dengan lahirnya Undang-undang No. 41 Tahun 2004 tentang wakaf dan Peraturan Pemerintah nomor 42 tahun 2006 tentang pelaksanan Undang-undang No. 41 Tahun 2004 tentang wakaf, merupakan salah satu upaya untuk memberdayakan wakaf yang merupakan salah satu instrumen dalam membangun kehidupan sosial ekonomi umat Islam serta memfasilitasi pemberdayaan wakaf secara berkesinambungan. Bagianbagian penting dari konsep pemberdayaan wakaf secara umum antara lain mengurangi tentang pemahaman yang komprehensif dan pola manajemen modern pemberdayaan potensi wakaf yang ada serta dalam rangka memberdayakan wakaf secara produktif.

\section{B. Perumusan Masalah}

1. Bagaimana praktik pengelolaan wakaf produktif di Pondok Pesantren Darunnajah Jakarta?

2. Apakah pengelolaan wakaf produktif terhadap peningkatan ekonomi Pondok Pesantren Darunnajah Jakarta sudah sesuai dengan peruntukannya?

3. Bagaimana pengaruh wakaf produktif terhadap peningkatan ekonomi di pesantren darunnajah Jakarta?

\section{Landasan Teori}

\section{Pengertian Wakaf Produktif}

Kata wakaf berasal dari bahasa Arab "وقف yang berarti : "tetap berdiri" atau "diam ditempat". (Suparman Usman,1999 : 23). Dalam istilah syara' wakaf adalah sejenis pemberian yang pelaksanaanya dilakukan dengan jalan menahan asal barang yang diwakafkan itu agar tidak diwariskan, digunakan dalam bentuk dijual, dihibahkan, digadai, disewakan, dipinjamkan dan sejenisnya. Sedangkan memanfaatnya adalah dengan menggunakannya sesuai dengan kehendak pemberi wakaf tanpa imbalan. (Muhammad 
Zawad Mughniyah, 1996 : 635). Definisi wakaf yang dibuat para ahli fikih pada umumnya memasukkan syarat-syarat wakaf sesuai dengan madzhab yang dianutnya. (Mundzir Qahaf, 2005 : 46). Pengikut mazhab Maliki menyebutkan bahwa wakaf itu tetap menjadi milik wakif dan adanya syarat tertentu ketika benda wakaf itu ada, untuk memperjelas manfaat wakaf agar memperoleh batasan waktu dalam wakaf. Sedangkan pengikut mazhab Syafi'i menekankan pada kalimat "terlepas dari campur tangan wakif dan tetap menjaga keutuhan wakaf" untuk memperjelas bahwa yang boleh diwakafkan adalah harta benda dan tidak termasuk manfaat barang serta bergantinya kepemilikan wakaf secara hukum menjadi milik Allah SWT. Adapun pengikut mazhab Hanafi mangatakan bahwa wakaf tetap menjadi milik wakif untuk memperjelas bahwa wakaf tidak bersifat harus dan diperbolehkannya wakif untuk mencabut wakaf kembali. Sedangkan orang yang mengambil pendapat dua sahabat Abu Hanifah, dalam definisinya menyebutkan bahwa secara hukum harta wakaf menjadi milik Allah SWT. Di sini Abdul Hadi tidak mengomentari definisi al-Muqanna, karena tidak menyebutkan syarat yang ada pada mazhab Hambali. ( (Mundzir Qahaf, 2005 : 48)

Di dalam Undang-Undang Nomor 41 Tahun 2004 tentang wakaf pada pasal 1 ayat (1), yang dimaksud dengan wakaf adalah perbuatan hukum wakif untuk memisahkan dan/atau menyerahkan sebagian harta benda miliknya untuk dimanfaatkan selamanya atau untuk jangka waktu tertentu sesuai dengan kepentingannya guna keperluan ibadah dan/atau kesejahteraan umum menurut syari'ah. (UU No.41 Tahun 2004, 3)

Pengertian wakaf menurut Mundzir Qahaf adalah menahan harta baik secara abadi maupun sementara untuk dimanfaatkan atau tidak langsung dan diambil manfaat hasilnya secara berulang-ulang dijalan kebaikan maupun khusus. (Mundzir Qahaf, 2005 : 52)

\section{Rukun dan Syarat Wakaf}

1. Wakif atau orang yang mewakafkan harta benda miliknya

2. Mauquh alaih atau nazhir atau orang yang menerima harta benda wakaf dari wakif untuk dikelola dan dikembangkan sesuai dengan peruntukannya

3. Mauquf atau harta benda yang memiliki daya tahan lama dan manfaat jangka panjang serta mempunyai nilai ekonomi menurut syariah yang diwakafkan oleh wakif

4. Shiqat atau Ikrar wakaf atau pernyataan kehendak wakif yang diucapkan secara lisan dan/atau tulisan kepada nazhir untuk mewakafkan harta benda miliknya. (UU no.41 tahun 2004).

\section{Macam - macam Wakaf Produktif}

1. Wakaf Sosial untuk kebaikan masyarakat (Khairi), yaitu apabila tujuan wakafnya untuk kepentingan umum

2. Wakaf Keluarga (Dzurri), yaitu apabila tujuan wakaf untuk memberi manfaat kepada wakif, keluarganya, keturunannya, dan orang-orang tertentu, tanpa melihat apakah kaya atau miskin, sakit atau sehat dan tua atau muda

3. Wakaf Gabungan (Musytarak), yaitu apabila tujuan wakafnya untuk umum dan keluarga secara bersamaan

4. Wakaf Abadi, yaitu apabila wakafnya berbentuk barang yang bersifat abadi, seperti tanah dan bangunan dengan tanahnya, atau barang bergerak yang ditentukan oleh wakif sebagai wakaf abadi dan produktif, dimana sebagian hasilnya untuk disalurkan sesuai tujuan wakaf, sedangkan sisanya untuk biaya perawatan wakaf dan mengganti kerusakannya

5. Wakaf Sementara, yaitu apabila barang yang diwakafkan berupa barang yang mudah rusak ketika dipergunakan tanpa memberi syarat untuk mengganti bagian yang rusak. Wakaf sementara juga bisa dikarenakan oleh keinginan wakif yang memberi batasan waktu ketika mewakafkan barangnya. 
6. Wakaf Langsung, yaitu wakaf yang pokok barangnya digunakan untuk mencapai tujuannya, seperti masjid untuk shalat, sekolah untuk kegiatan belajar-mengajar, rumah sakit untuk mengobati orang sakit dan lain sebagainya.

7. Wakaf Produktif, yaitu wakaf yang pokok barangnya digunakan untuk kegiatan produksi dan hasilnya diberikan sesuai dengan tujuan wakaf

\section{Tujuan Wakaf Produktif}

1. Untuk tujuan kebaikan

2. Tidak untuk tujuan maksiat yang diharamkan oleh syari'at atau undang-undang atau tradisi yang berlaku

3. Tidak bertentangan dengan undang-undang dan tradisi yang berlaku

\section{Metodologi Penelitian}

\section{Jenis Penelitian}

Dalam penelitian ini, penulis menggunakan metode penelitian kualitatif. Data kualitatif yaitu metode penelitian yang data - datanya dinyatakan dalam bentuk kata-kata atau kalimat, skema dan gambar. Metode penelitian ini bersifat deskriptif, karena data yang dianalisa itu berupa deskripsi dari gejala-gejala yang diamati. Dalam proses penelitian, akan bersifat penelitian evaluatif terhadap praktik wakaf produktif pada Yayasan Pondok Pesantren Darunnajah Jakarta. Sedangkan data kuantitatif yaitu data yang berbentuk angka.

\section{Sumber data}

Dalam penyusunan skripsi ini, penulis menggunakan dua jenis sumber data, yaitu :

1. Data primer

Merupakan data yang diperoleh langsung dari hasil wawancara pihak Yayasan Pondok Pesantren Darunnajah Jakarta, yaitu hasil saldo laporan keuangan unit-unit usaha Pondok Pesantren Darunnajah Jakarta dari tahun 2005-2007.

2. Data sekunder

Merupakan data yang diperoleh dari literatur - literatur kepustakaan seperti buku buku serta sumber lainnya yang berkaitan dengan materi penulisan skripsi ini.

\section{Teknik Pengumpulan Data}

Sesuai dengan permasalahan yang diangkat, maka dalam pengumpulan data skripsi ini, penulis menggunakan penelitian sebagai berikut:

1. Penelitian kepustakaan (library research), dalam hal ini penulis mengadakan penelitian terhadap beberapa literatur yang ada kaitannya dengan penulisan skripsi ini, literatur ini berupa skripsi terdahulu, buku - buku, majalah, surat kabar, artikel, buletin, internet dan lain sebagainya. Langkah dalam melaksanakan studi kepustakaan ini adalah dengan cara membaca, mengutip, untuk menganalisa dan merumuskan hal - hal yang dianggap perlu dalam memenuhi data dalam penelitian ini.

2. Penelitian lapangan (field research), dalam hal ini untuk mendapatkan data - data dan informasi tentang aplikasi pengelolaan dana wakaf produktif dalam peningkatan perekonomian pesantren. Penulis langsung ke objek penelitian yaitu pada nazhir atau lembaga Yayasan Pondok Pesantren Darunnajah Jakarta dengan menggunakan tekhnik pengumpulan sebagai berikut :

a) Interview, yaitu dengan melakukan wawancara dengan pihak - pihak yang terlibat dalam penelitian ini baik secara langsung maupun tidak langsung.

b) Dokumentasi, yaitu mengumpulkan data berdasarkan laporan yang didapat dari nazhir atau lembaga yang diteliti dan laporan lainnya yang berkaitan dengan masalah penelitian ini. 


\section{Teknik Analisa Data}

Dalam pengelolaan dan pengembangan suatu aktifitas memerlukan suatu perencanaan strategis, yaitu suatu pola atau struktur sasaran yang saling mendukung dan melengkapi ke arah tujuan yang menyeluruh. Sebagai persiapan perencanaan, agar dapat memilih dan menetapkan strategi dan sasaran sehingga tersusun program-program dan proyek-proyek yang efektif dan efesien, maka diperlukan suatu analisis yang tajam dari para pengurus organisasi. Salah satu analisis yang cukup populer di kalangan pelaku organisasi adalah analisis SWOT.

Analisis SWOT adalah sebuah bentuk analisis situasi dan kondisi yang bersifat deskriptif (memberi gambaran). Analisa ini menempatkan situasi dan kondisi sebagai faktor masukan yang kemudian dikelompokkan menurut kontribusisnya masing-masing. Suatu hal yang harus diingat baik-baik oleh para pengguna analisa SWOT, bahwa analisa SWOT adalah semata-mata hanya sebuah alat analisa yang ditujukan untuk menggambarkan situasi yang sedang dihadapi atau yang mungkin akan dihadapi oleh organisasi dan bukan sebuah alat analisa ajaib yang mampu memberikan jalan keluar yang cepat bagi masalah-masalah yagn dihadapi oleh organisasi.

Analisa ini terbagi atas empat komponen dasar yaitu :

1. $S=$ Strength adalah situasi atau kondisi yang merupakan kekuatan dari organsisasi atau program pada saat ini

2. $\mathrm{W}=$ Weakness adalah situasi atau kondisi yang merupakan kelemahan dari organisasi atau program pada saat ini

3. $\mathrm{O}=$ Opportunity adalah situasi atau kondisi yang merupakan peluang di luar organisasi dan memberikan peluang berkembang bagi organisasi di masa depan

4. $\mathrm{T}=$ Threat adalah situasi yang merupakan ancaman bagi organisasi yang datang dari luar organisasi dan dapat mengancam eksistensi organisasi di masa depan

Maksud dari analisis SWOT ini ialah untuk meneliti dan menentukan dalam hal manakah "yayasan"

1. Kuat (sehingga dapat dioptimalkan)

2. Lemah (sehingga dapat segera dibenahi)

3. Kesempatan-kesempatan di luar (untuk dimanfaatkan)

4. Ancaman-ancaman dari luar (untuk diantisipasi)

5. Bagan interaksi analisa SWOT

\section{Analisis Regresi Sederhana}

Teknik analisis regresi sederhana digunakan untuk mengetahui pengaruh antara wakaf produktif dengan ekonomi pesantren darunnajah. Dengan persamaan regresi $\mathrm{Y}=\mathrm{a}+\mathrm{b} 1 \mathrm{X} 1+\mathrm{X} 2 \mathrm{~b} 2$.

Teknik pengujian hipotesis menggunakan uji parsial dan uji simultan dengan tekhnik probabilitas dengan cara membandingkan nilai probabilitas sig dengan taraf signifikan 0,05. jika nilai probabilitas sig $<0,05$ maka signifikan.

\section{E. Hasil dan Pembahasan Penelitian Asset wakaf pesantren darunnajah darunnajah}

\begin{tabular}{|c|c|c|c|c|c|}
\hline Daerah & Lokasi & $\begin{array}{c}\text { Status/ } \\
\text { atas nama }\end{array}$ & Keterangan & $\begin{array}{l}\text { Luas } \\
\text { (m2) }\end{array}$ & (Rupiah) \\
\hline \multirow[b]{4}{*}{ Jakarta } & $\begin{array}{l}\text { Pesantren Darunnajah } \\
\text { Ulujami }\end{array}$ & $\begin{array}{l}\text { Wakaf/ Yayasan } \\
\text { Darunnajah }\end{array}$ & $\begin{array}{l}\text { Tanah dan } \\
\text { Bangunan } \\
\end{array}$ & 38.085 & $1,904,250,000$. \\
\hline & $\begin{array}{l}\text { Jl. Ulujami Raya No. } 87 \\
\text { Pesangrahan }\end{array}$ & $\begin{array}{l}\text { Milik Yayasan/ } \\
\text { Bule }\end{array}$ & $\begin{array}{l}\text { Tanah dan } \\
\text { Bangunan } \\
\end{array}$ & 400 & $20,000,000$. \\
\hline & $\begin{array}{l}\text { Jakarta/ Gedung Abu } \\
\text { Bakar Shiddiq }\end{array}$ & & & & \\
\hline & $\begin{array}{l}\text { Jl. Ulujami Raya No. } 87 \\
\text { Pesangrahan }\end{array}$ & $\begin{array}{l}\text { Milik Yayasan/ } \\
\text { Murtiningsih }\end{array}$ & $\begin{array}{l}\text { Tanah dan } \\
\text { Bangunan }\end{array}$ & 397 & $19,850,000$ \\
\hline
\end{tabular}




\begin{tabular}{|c|c|c|c|c|c|}
\hline & $\begin{array}{l}\text { Jakarta/ Gedung } \\
\text { Palestina }\end{array}$ & & & & \\
\hline & Belakang Pesantren & Milik Yayasan & Tanah & 750 & $37,500,000$. \\
\hline & $\begin{array}{l}\text { Jl. Ciledug Raya No. } 1 \\
\text { Ulujami }\end{array}$ & $\begin{array}{l}\text { Wakaf/ Yayasan } \\
\text { Darunnajah }\end{array}$ & $\begin{array}{l}\text { Tanah dan } \\
\text { Bangunan }\end{array}$ & 1.500 & $75,000,000$ \\
\hline & $\begin{array}{l}\text { Jakarta Selatan/ Ruko } \\
\text { Darunnajah Cipulir }\end{array}$ & & & & \\
\hline & Jl. H. Gari Bintaro & $\begin{array}{l}\text { Wakaf/Yayasan } \\
\text { Darunnajah }\end{array}$ & Tanah & 1.400 & $70,000,000$. \\
\hline & Jl. H. Gari Bintaro & Milik Yayasan & Tanah & 1.000 & $50,000,000$ \\
\hline & $\begin{array}{l}\text { Jl. Kebayoran Lama No. } \\
310 \text { Sukabumi } \\
\text { Ilir Jakarta Selatan }\end{array}$ & Wakaf/ Hj. Soraya & $\begin{array}{l}\text { Tanah dan } \\
\text { Bangunan }\end{array}$ & 3.335 & $166,750,000$ \\
\hline & JUMLAH & & & 46.867 & $2,343,350,000$. \\
\hline & $\begin{array}{l}\text { Jl. Pesantren Jurang } \\
\text { Mangu }\end{array}$ & $\begin{array}{l}\text { Milik Yayasan/ H. } \\
\text { Saifudin Arief }\end{array}$ & Tanah & 255 & $12,750,000$ \\
\hline & $\begin{array}{l}\text { Gg. H Umar Rt. 04/ } 05 \\
\text { Pondok Aren }\end{array}$ & $\begin{array}{l}\text { Milik Yayasan/ H. } \\
\text { Saifudin Arief }\end{array}$ & Tanah & 2.255 & $112,750,000$. \\
\hline & $\begin{array}{l}\text { Gg. H Umar Rt. 04/ } 05 \\
\text { Pondok Aren }\end{array}$ & $\begin{array}{l}\text { Milik Yayasan/ H. } \\
\text { Saifudin Arief }\end{array}$ & $\begin{array}{l}\text { Tanah dan } \\
\text { Bangunan }\end{array}$ & 354 & $17,700,000$ \\
\hline & $\begin{array}{l}\text { Gg. H Umar Rt. 04/ } 05 \\
\text { Pondok Aren }\end{array}$ & $\begin{array}{l}\text { Milik Yayasan/ } \\
\text { Drs. Sofwan } \\
\text { Manaf } \\
\end{array}$ & $\begin{array}{l}\text { Tanah dan } \\
\text { Bangunan }\end{array}$ & 230 & $11,500,000$. \\
\hline & $\begin{array}{l}\text { Perumahan Ciledug } \\
\text { Indah I Jl. Buana II } \\
\text { Blok BB } 5 \text { No. } 72\end{array}$ & $\begin{array}{l}\text { Wakaf/ Fieke } \\
\text { Luthfia }\end{array}$ & $\begin{array}{l}\text { Tanah dan } \\
\text { Bangunan }\end{array}$ & 106 & $5,300,000$. \\
\hline Tangerang & $\begin{array}{l}\text { Ruko Perumahan Citra } \\
\text { Raya }\end{array}$ & $\begin{array}{l}\text { Milik Yayasan/ } \\
\text { Drs. Sofwan } \\
\text { Manaf }\end{array}$ & Tanah & 48 & $2,400,000$. \\
\hline & Pamulang Timur & Hj. Maesaroh & $\begin{array}{l}\text { Tanah dan } \\
\text { Bangunan }\end{array}$ & 6.800 & $340,000,000$ \\
\hline & JUMLAH & & & 10.018 & $500,900,000$ \\
\hline & $\begin{array}{l}\text { Pesantren Darunnajah } 2 \\
\text { Cipining }\end{array}$ & $\begin{array}{l}\text { Wakaf/Yayasan } \\
\text { Darunnajah }\end{array}$ & $\begin{array}{l}\text { Tanah dan } \\
\text { Bangunan }\end{array}$ & 700.000 & $35,000,000,000$. \\
\hline Bogor & $\begin{array}{l}\text { Pesantren Annur } \\
\text { (Darunnajah 8) Cidokom }\end{array}$ & Wakaf & $\begin{array}{l}\text { Tanah dan } \\
\text { Bangunan }\end{array}$ & 25.000 & $1,250,000,000$ \\
\hline & JUMLAH & & & 725.000 & $36,250,000,000$. \\
\hline & $\begin{array}{l}\text { Desa Pabuaran, Kec } \\
\text { Pabuaran }\end{array}$ & $\begin{array}{l}\text { Wakaf/ Yayasan } \\
\text { Darunnajah }\end{array}$ & Tanah & 510 & $25,500,000$. \\
\hline & $\begin{array}{l}\text { Desa Pabuaran, Kec } \\
\text { Pabuaran }\end{array}$ & $\begin{array}{l}\text { Wakaf/Yayasan } \\
\text { Darunnajah }\end{array}$ & $\begin{array}{l}\text { Tanah dan } \\
\text { Bangunan }\end{array}$ & 1.475 & $73,750,000$. \\
\hline & $\begin{array}{l}\text { Desa Pabuaran, Kec } \\
\text { Pabuaran }\end{array}$ & $\begin{array}{l}\text { Wakaf/ Yayasan } \\
\text { Darunnajah }\end{array}$ & $\begin{array}{l}\text { Tanah dan } \\
\text { Bangunan }\end{array}$ & 3.440 & $172,000,000$. \\
\hline & $\begin{array}{l}\text { Desa Pabuaran, Kec } \\
\text { Pabuaran }\end{array}$ & $\begin{array}{l}\text { Wakaf/Yayasan } \\
\text { Darunnajah }\end{array}$ & Tanah & 1.390 & $69,500,000$. \\
\hline & $\begin{array}{l}\text { Desa Pabuaran, Kec } \\
\text { Pabuaran }\end{array}$ & $\begin{array}{l}\text { Wakaf/Yayasan } \\
\text { Darunnajah }\end{array}$ & Sawah & 1.276 & $63,800,000$ \\
\hline & $\begin{array}{l}\text { Desa Pabuaran, Kec } \\
\text { Pabuaran }\end{array}$ & $\begin{array}{l}\text { Wakaf/Yayasan } \\
\text { Darunnajah }\end{array}$ & Sawah & 1.490 & $74,500,000$. \\
\hline & $\begin{array}{l}\text { Desa Pesangrahan, Kec } \\
\text { Pabuaran }\end{array}$ & $\begin{array}{l}\text { Wakaf/Yayasan } \\
\text { Darunnajah }\end{array}$ & Sawah & 750 & $37,500,000$. \\
\hline & $\begin{array}{l}\text { Desa Pesangrahan, Kec } \\
\text { Pabuaran }\end{array}$ & $\begin{array}{l}\text { Wakaf/Yayasan } \\
\text { Darunnajah }\end{array}$ & Sawah & 1.687 & $84,350,000$. \\
\hline Serang & $\begin{array}{l}\text { Desa Pesangrahan, Kec } \\
\text { Pabuaran }\end{array}$ & Wakaf & Sawah & 1.220 & $61,000,000$ \\
\hline & $\begin{array}{l}\text { Desa Pesangrahan, Kec } \\
\text { Pabuaran }\end{array}$ & Wakaf & Ladang & 930 & $46,500,000$ \\
\hline & $\begin{array}{l}\text { Desa Pesangrahan, Kec } \\
\text { Pabuaran }\end{array}$ & Wakaf & Ladang & 3.830 & $191,500,000$. \\
\hline & Desa Pesangrahan, Kec & Wakaf & Sawah & 380 & \\
\hline
\end{tabular}




\begin{tabular}{|c|c|c|c|c|c|}
\hline & Pabuaran & & & & $19,000,000$. \\
\hline & $\begin{array}{l}\text { Desa Pesangrahan, Kec } \\
\text { Pabuaran }\end{array}$ & $\begin{array}{l}\text { Milik Yayasan/ H. } \\
\text { Abdul Manaf }\end{array}$ & & 11.520 & $576,000,000$. \\
\hline & $\begin{array}{l}\text { Desa Pesangrahan, Kec } \\
\text { Pabuaran }\end{array}$ & $\begin{array}{l}\text { Milik Yayasan/ H. } \\
\text { Abdul Manaf }\end{array}$ & & 13.050 & $652,500,000$. \\
\hline & Sindang Heula & $\begin{array}{l}\text { Milik Yayasan/ H. } \\
\text { Abdul Manaf }\end{array}$ & & 4.000 & $200,000,000$. \\
\hline & $\begin{array}{l}\text { Desa Sindang Heula, } \\
\text { Kec Pabuaran }\end{array}$ & $\begin{array}{l}\text { Milik Yayasan/ H. } \\
\text { Abdul Manaf }\end{array}$ & & 5.465 & $273,250,000$. \\
\hline & $\begin{array}{l}\text { Desa Sindang Heula, } \\
\text { Kec Pabuaran }\end{array}$ & $\begin{array}{l}\text { Milik Yayasan/ Hj. } \\
\text { Soraya }\end{array}$ & & 3.000 & $150,000,000$. \\
\hline & $\begin{array}{l}\text { Desa Sindang Heula, } \\
\text { Kec Pabuaran }\end{array}$ & $\begin{array}{l}\text { Milik Yayasan/ H. } \\
\text { Abdul Manaf }\end{array}$ & & 3.565 & $178,250,000$. \\
\hline & $\begin{array}{l}\text { Desa Sindang Heula, } \\
\text { Kec Pabuaran }\end{array}$ & $\begin{array}{l}\text { Milik Yayasan/ } \mathrm{H} \text {. } \\
\text { Abdul Manaf }\end{array}$ & & 2.064 & $103,200,000$. \\
\hline & $\begin{array}{l}\text { Desa Sindang Heula, } \\
\text { Kec Pabuaran }\end{array}$ & $\begin{array}{l}\text { Milik Yayasan/ H. } \\
\text { Abdul Manaf }\end{array}$ & & 4.000 & $200,000,000$. \\
\hline & $\begin{array}{l}\text { Desa Sindang Heula, } \\
\text { Kec Pabuaran }\end{array}$ & $\begin{array}{l}\text { Milik Yayasan/ H. } \\
\text { Abdul Manaf }\end{array}$ & & 3.700 & $185,000,000$. \\
\hline & $\begin{array}{l}\text { Desa Sindang Heula, } \\
\text { Kec Pabuaran }\end{array}$ & $\begin{array}{l}\text { Milik Yayasan/ } \\
\text { drg. Munifah }\end{array}$ & Sawah & 1.780 & $89,000,000$. \\
\hline & $\begin{array}{l}\text { Desa Sindang Heula, } \\
\text { Kec Pabuaran }\end{array}$ & $\begin{array}{l}\text { Milik Yayasan/ H. } \\
\text { Abdul Manaf }\end{array}$ & Rumah & 100 & $5,000,000$. \\
\hline & $\begin{array}{l}\text { Desa Sindang Heula, } \\
\text { Kec Pabuaran }\end{array}$ & Milik Yayasan & Sawah & 300 & $15,000,000$. \\
\hline & $\begin{array}{l}\text { Desa Sindang Heula, } \\
\text { Kec Pabuaran }\end{array}$ & Milik Yayasan & Sawah & 1.120 & $56,000,000$ \\
\hline & Citasuk & Wakaf & & 2.890 & $144,500,000$. \\
\hline & Citasuk & Wakaf & & 990 & $49,500,000$. \\
\hline & Citasuk & Wakaf & & 1.180 & $59,000,000$. \\
\hline & Citasuk & Wakaf & & 360 & $18,000,000$. \\
\hline & Citasuk & Wakaf & & 560 & $28,000,000$. \\
\hline & $\begin{array}{l}\text { Ruko Perumahan } \\
\text { Serang Baru }\end{array}$ & $\begin{array}{l}\text { Milik Yayasan/ } \\
\text { Drs. Sofwan } \\
\text { Manaf }\end{array}$ & $\begin{array}{l}\text { Tanah dan } \\
\text { Bangunan }\end{array}$ & 96 & 4,800,000. \\
\hline & Ruko Widya Asri & $\begin{array}{l}\text { Milik Yayasan/ } \\
\text { Drs. Sofwan } \\
\text { Manaf }\end{array}$ & $\begin{array}{l}\text { Tanah dan } \\
\text { Bangunan }\end{array}$ & 62 & $3,100,000$. \\
\hline & Ruko Citra Raya & $\begin{array}{l}\text { Milik Yayasan/ } \\
\text { Drs. Sofwan } \\
\text { Manaf }\end{array}$ & $\begin{array}{l}\text { Tanah dan } \\
\text { Bangunan }\end{array}$ & 48 & $2,400,000$. \\
\hline & JUMLAH & & & 71.681 & $3,584,050,000$. \\
\hline Bekasi & Duren Raya & Milik Yayasan & $\begin{array}{l}\text { Tanah dan } \\
\text { Bangunan }\end{array}$ & 255 & $11,250,000$. \\
\hline Sukabumi & $\begin{array}{l}\text { Villa II Darunnajah, } \\
\text { Cipanas }\end{array}$ & Milik Yayasan & $\begin{array}{l}\text { Tanah dan } \\
\text { Bangunan }\end{array}$ & & \\
\hline Bandung & $\begin{array}{l}\text { Villa I Darunnajah, } \\
\text { Bandung }\end{array}$ & $\begin{array}{l}\text { Wakaf/ H. } \\
\text { Syaipudin, } \\
\text { Mayestik }\end{array}$ & Tanah & & \\
\hline Pandeglang & $\begin{array}{l}\text { Desa Tunjungan, } \\
\text { Cekeusik }\end{array}$ & Milik Yayasan & Tanah & 20.000 & $1,000,000,000$. \\
\hline Lampung & Mesuji, Lampung & Milik Yayasan & Tanah & 25.000 & $1,250,000,000$. \\
\hline & $\begin{array}{l}\text { Perkebunan Kelapa } \\
\text { Sawit Bengkulu }\end{array}$ & Wakaf & Perkebunan & 2.000 .000 & $100,000,000,000$. \\
\hline Bengkulu & $\begin{array}{l}\text { Desa Babatan Sukaraja } \\
\text { Seluma }\end{array}$ & Wakaf & $\begin{array}{l}\text { Tanah dan } \\
\text { Perkebunan }\end{array}$ & 65.000 & $3,250,000,000$. \\
\hline Nunukan & Nunukan & Wakaf & Tanah & 2.100 .000 & $10,500,000,000$ \\
\hline & JUMLAH & & & 4.210 .225 & $210,511,250,000$ \\
\hline & TOTAL & & & 5.063.791 & $253,189,550,000$ \\
\hline
\end{tabular}

Sumber : Dari pihak yayasan darunnajah Jakarta 2007 
Peruntukkan wakaf Unit usaha pesantren darunnajah serta laporan keuangan :

\begin{tabular}{|c|l|c|c|c|}
\hline No & Jenis usaha & 2005 & 2006 & 2007 \\
\hline 1 & Koperasi & 15.239 .000 .000 & 122.228 .000 .000 & 81.996 .000 .000 \\
\hline 2 & Dapur umum & 10.980 .000 .000 & 11.080 .000 .000 & 13.080 .000 .000 \\
\hline 3 & Kantin & 78.400 .000 & 89.125 .000 & 50.621 .000 \\
\hline 4 & BMT & 25.151 .000 .000 & 59.770 .000 .000 & 251.000 .000 .000 \\
\hline 5 & PH & 14.000 .000$. & 37.000 .000 & 49.000 .000 \\
\hline 6 & D Smart & 5.400 .000 & 5.000 .000 & 19.875 .000 \\
\hline 7 & Alfa Mart DN & 3.451 .500 .000 & 3.682 .500 .000 & 3.800 .000 .000 \\
\hline 8 & DN Tour \& Travel & 63.000 .000 & 94.500 .000 & 35.000 .000 \\
\hline 9 & Wartel & 7.000 .000 & 15.000 .000 & 26.000 .000 \\
\hline 10 & Warnet & 4.000 .000 & 2.000 .000 & 3.400 .000 \\
\hline 11 & Rental Car & 6.710 .000 & 3.800 .000 & 6.500 .000 \\
\hline 12 & Klinik DN & 4.000 .000 & 5.000 .000 & 11.000 .000 \\
\hline 13 & Photocopy & 6.000 .000 & 7.000 .000 & 6.500 .000 \\
\hline 14 & Azalea Baber Shop & 2.000 .000 & 8.500 .000 & 15.000 .000 \\
\hline 15 & Laundry & 2.000 .000 & 3.000 .000 & 5.000 .000 \\
\hline 16 & Parkir & 3.000 .000 & 2.600 .000 & 3.600 .000 \\
\hline & Jumlah & $\underline{\mathbf{5 5 . 0 1 7 . 0 1 0 . 0 0 0}}$ & $\underline{\mathbf{1 9 7 . 0 3 3 . 0 2 5 . 0 0 0}}$ & $\underline{\mathbf{3 5 0 . 1 0 7 . 4 9 6 . 0 0 0}}$ \\
\hline
\end{tabular}

Keuangan wakaf produktif pesantren darunnajah

\begin{tabular}{|c|c|c|}
\hline Tahun & Wakaf Produktif (X) (Rp) & Saldo Tahunan Badan-badan Usaha (Y) (Rp) \\
\hline 2005 & 2.844 .250 .000 & 55.017 .010 .000 \\
\hline 2006 & 39.834 .050 .000 & 197.033 .025 .000 \\
\hline 2007 & 210.511 .250 .000 & 350.107 .496 .000 \\
\hline
\end{tabular}

Sumber : dari pihak yayasan darunnajah jakarta 2007

Untuk menghitung persamaan regresinya, maka diperlukan tabel penolong

Nilai Wakaf Produktif Dan Nilai Ekonomi Pesantren darunnajah

\begin{tabular}{|c|c|c|c|}
\hline TH & $X_{1}$ & $Y_{1}$ & $\mathbf{X}_{1} \mathbf{Y}_{1}$ \\
\hline 2005 & $2,844,250,000$ & $55,017,010,000$ & $156,482,130,692,500,000,000$ \\
\hline 2006 & $39,834,050,000$ & $197,033,025,000$ & $7,848,623,369,501,250,000,000$ \\
\hline 2007 & $210,511,250,000$ & $350,107,496,000$ & $73,701,566,617,330,000,000,000$ \\
\hline JMLH & $253,189,550,000$ & $602,157,531,000$ & $81,706,672,117,523,800,000,000$ \\
\hline
\end{tabular}




\begin{tabular}{|c|c|c|}
\hline TH & $X_{1}{ }^{2}$ & $Y_{1}^{2}$ \\
\hline 2005 & $8,089,758,062,500,000,000$ & $3,026,871,389,340,100,000,000$ \\
\hline 2006 & $1,586,751,539,402,500,000,000$ & $38,822,012,940,650,600,000,000$ \\
\hline 2007 & $44,314,986,376,562,500,000,000$ & $122,575,258,755,390,000,000,000$ \\
\hline JMLH & $45,909,827,674,027,500,000,000$ & $164,424,143,085,381,000,000,000$ \\
\hline
\end{tabular}

Menghitung harga a dan $b$ dengan rumus :

Rumus harga a :

$$
\frac{\mathrm{a}=\left(\sum \mathrm{Y}_{\mathrm{I}}\right)\left(\sum \mathrm{X}_{\mathrm{I}}^{2}\right)-\left(\sum \mathrm{X}_{\mathrm{I}}\right)\left(\sum \mathrm{X}_{\mathrm{I}} \mathrm{Y}_{\mathrm{I}}\right)}{\mathrm{n} \sum \mathrm{X}_{\mathrm{I}}^{2}-\left(\sum \mathrm{X}_{\mathrm{I}}\right)^{2}}
$$

$$
\begin{aligned}
\mathrm{a}= & \frac{(602,157,531,000)(45,909,827,674,027,500,000,000)-}{(253,189,550,000)(81,706,672,117,523,800,000,000} \\
& (3)(45,909,827,674,027,500,000,000)-(253,189,550,000)^{2} \\
= & \underline{\mathbf{7 5 , 7 7 5 , 4 1 9 , 8 6 0}}
\end{aligned}
$$

$$
\text { Rumus harga } \mathrm{b}: \frac{\mathrm{b}=\mathrm{n} \sum \mathrm{X}_{\mathrm{I}} \mathrm{Y}_{\mathrm{I}}-\left(\sum \mathrm{X}_{\mathrm{I}}\right)\left(\sum \mathrm{Y}_{\mathrm{I}}\right)}{\mathrm{n} \sum \mathrm{X}_{\mathrm{I}}^{2}-\left(\sum \mathrm{X}_{\mathrm{I}}\right)^{2}}
$$

$$
b=\frac{(3) 81,706,672,117,523,800,000,000-(253,189,550,000)}{(602,157,531,000)}
$$

Setelah harga a dan b ditemukan, maka persamaan regresi linier sederhana dapat disusun. Persamaan regresi nilai wakaf produktif dan nilai ekonomi pesantren adalah sebagai berikut : $\tilde{Y}=75,775,419,860+1.779720732(X)$.

Persamaan regresi yang telah ditemukan dapat digunakan untuk melakukan prediksi (ramalan) bagaimana hasil variabel dependen akan terjadi bila hasil dalam variabel independen ditetapkan. Misalnya nilai wakaf produktif $=$ Rp.36,250,000,000, maka nilai rata-rata ekonomi pesantren setiap tahun adalah $: \tilde{Y}=75,775,419,860+1.779720732$ $(36,250,000,000)=140,290,296,395$.

Jadi diperkirakan nilai rata-rata ekonomi pesantren setiap tahun sebesar Rp. $140,290,296,395$. Dari persamaan regresi di atas dapat diartikan bahwa, bila nilai wakaf produktif bertambah 1, maka nilai rata-rata ekonomi pesantren setiap tahun akan bertambah 1.779720732 atau seitap nilai wakaf produktif bertambah 10 maka nilai ratarata ekonomi pesantren akan bertambah sebesar 17.79720732 .

Membuat garis regresi dapat digambarkan berdasarkan persamaan yang telah ditemukan adalah : $\tilde{Y}=75,775,419,860+1.779720732(X)$ 


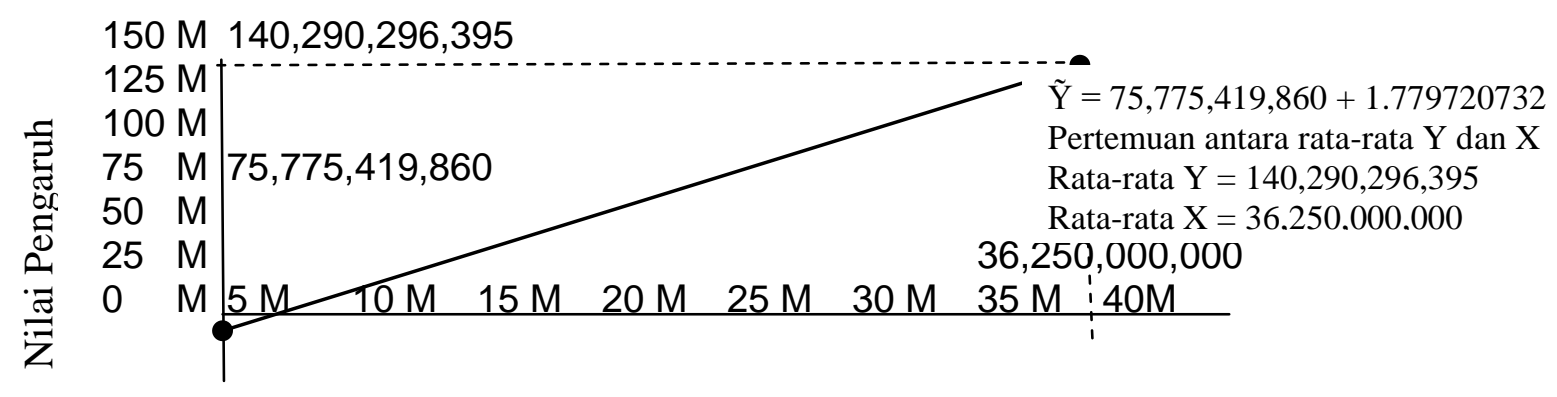

Nilai Ekonomi Pesantren

\section{Tabel 4.3 Garis Regresi Nilai Wakaf Produktif Dan Nilai Ekonomi Pesantren}

Antara nilai wakaf produktif dengan nilai ekonomi pesantren dapat dihitung korelasinya. Korelasi dapat dihitung dengan rumus yang telah diberikan (rumus harga b). Rumus harga $b$ :

$$
\mathrm{b}=\frac{\mathrm{n} \sum \mathrm{X}_{\mathrm{I}} \mathrm{Y}_{\mathrm{I}}-\left(\sum \mathrm{X}_{\mathrm{I}}\right)\left(\sum \mathrm{Y}_{\mathrm{I}}\right)}{\mathrm{n} \sum \mathrm{X}_{\mathrm{I}}^{2}-\left(\sum \mathrm{X}_{\mathrm{I}}\right)^{2}}
$$

$$
\begin{aligned}
b= & \frac{(3) 81,706,672,117,523,800,000,000-(253,189,550,000)}{(602,157,531,000)} \\
& (3) 45,909,827,674,027,500,000,000-(253,189,550,000)^{2}=\underline{\mathbf{1 . 7 7 9 7 2 0 7 3 2}}
\end{aligned}
$$

Harga $r$ (Koefisien korelasi product moment antara variable $X$ dengan variabel $Y$ ) tabel untuk taraf kesalahan $5 \%$ dengan $n=3$ diperoleh 0.997 dan untuk $1 \%=0.999$. karena harga $r$ hitung lebih besar dari $r$ tabel baik untuk kesalahal 5\% maupun 1\% $(1.779720732>0.999>0.997)$, maka dapat diduga terdapat hubungan yang positif dan signifikan sebesar 1.779720732 antara nilai wakaf produktif dengan nilai ekonomi pesantren setiap tahun.

Koefisien determinasinya $r^{2}=1.779720732^{2}=3.167405883910615824$. Hal ini berarti nilai rata-rata ekonomi pesantren setiap tahun $316.74 \%$ ditentukan oleh nilai wakaf produktif yang diberikan melalui persamaan regresi $\tilde{Y}=75,775,419,860+1.779720732$ (X) sisanya $-216.74 \%$ ditentukan oleh faktor lain.

\section{H. Kesimpulan}

Berdasarkan paparan data dan pembahasan hasil penelitian, maka secara umum dapat disimpulkan beberapa hal yaitu :

1. Dalam praktiknya, kegiatan pengelolaan wakaf di Pondok Pesantren Darunnajah Jakarta bertujuan untuk mencapai tujuan produksi, bisnis dan sosial. Kegiatan ini juga menyerupai wakaf yang menginvestasikan hartanya untuk memperoleh keuntungan yang diberikan kepada orang-orang yang berhak atas manfaat wakaf ini. Hal ini dapat dilihat dari banyaknya asset wakaf yang dimiliki oleh Yayasan Darunnajah serta didirikan bidang-bidang usaha yang dibangun diatas tanah wakaf sebanyak 16 bidang-bidang usaha yang meliputi bidang lembaga pendidikan, ekonomi dan kesehatan untuk kepentingan sarana dan prasarana di dalam Pondok Pesantren Darunnajah Jakarta, menambah asset wakaf Yayasan Darunnajah yang sejauh ini sudah mencapai $5.063 .791 \mathrm{~m}^{2}$, untuk memberikan bantuan beasiswa kepada ashabunnajah sebanyak 80 santri, kesejateraan guru dan karyawan sebanyak 334 orang. Sumber dana yang diperoleh dalam pengelolaan wakaf produktif untuk 
membangun bidang-bidang usaha di dapat dari Yayasan Darunnajah sendiri. Hasil dari bidang-bidang usaha diaudit langsung oleh internal audit pesantren.

2. Strategi yang diambil dalam meningkatkan ekonomi pesantren yang diperoleh dari wakaf produktif dengan cara : Meningkatkan kelayakan produksi harta wakaf hingga mencapai target yang maksimal untuk memberi manfaat sebesar mungkin, melindungi pokok-pokok harta wakaf dengan adanya pemeliharaan dan penjagaan yang baik dalam menginvestasikan harta wakaf dan mengurangi sekecil mungkin resiko, melaksanakan tugas distribusi hasil wakaf dengan baik kepada tujuan wakaf yang telah ditentukan, berpegang teguh kepada syarat-syarat wakif, baik berupa tujuan wakaf, pengenalan objek dan batasan tempatnya dan bentuk kepengurusan, memberikan penjelasan kepada para dermawan dan mendorong mereka untuk dapat mempercayakan harta wakaf mereka kepada pihak Yayasan Darunnajah, baik secara lisan maupun dengan cara member keteladanan.

Wakaf produktif sangat berpengaruh terhadap peningkatan Ekonomi Pesantren Darunnajah Jakarta. Hal ini dapat dilihat dari meningkatnya persen tase saldo laporan keuangan, yang semula dari tahun 2005 sebesar Rp. 55.017.010.000 (9\%) menjadi Rp. 197.033.025.000 (33\%) di tahun 2006 dan di tahun 2007 meningkat menjadi Rp. 350.107.496.000 (58\%). Hal ini terjadi dikarenakan bertambahnya asset wakaf dari tahun ke tahun yang diberikan oleh para dermawan kepada pihak Yayasan Darunnajah untuk dapat dikelola dengan baik dan memaksimalkan asset wakaf sebaik mungkin dengan cara membuka unit-unit usaha untuk membangun sarana dan prasarana, memberikan beasiswa, memberikan bantuan kepada fakir miskin,anak terlantar, yatim piatu dan untuk mensejahterakan umat.

\section{Daftar Pustaka}

Arifin, Muhammad, Kapita Selekta Pendidikan (Sistem dan Umum), Jakarta : Bumi aksara, 1991.

Albani, al, Muhammad Nashirudin, Mukhtasar Shahih Musli, Beirut : Al Maktab Al Islami tt.

Bulletin Darunnajah, Media Informasi Tahunan, edisi XXI, Jakarta : Pesantren Darunnajah Jakarta jl. Ulujami Raya No. 86 Pesangrahan Jakarta Selatan, Juni 2007.

Dahlan, Abdul Aziz, dkk, ed Ensiklopedia Hukum Islam,, Jakarta : PT Ichtiar Baru Van Hoeve, 2003

Departemen Agama RI, Al-Qur'an dan Terjemah, Bandung : Syamil Internasional, 2007. Panduan Pemberdayaan Tanah Wakaf Produktif Strategis Di Indonesia, Jakarta : Direktorat Jenderal Bimbingan Masyarakat Islam 2006.

Pedoman Pengelolaan 'dan Pengembangan Wakaf, Jakarta : Direktorat Pemberdayaan Wakaf Direktorat Jenderal Bimbingan Masyarakat Islam, 2006.

Undang - Undang Nomor 41 Tahun 2004 Tentang Wakaf dan Peraturan Pemerintah Nomor 42 Tahun 2006 Tentang Pelaksanaan Undangundang Nomor 41 Tahun 2004 Tentang Wakaf, Jakarta : Direktorat Jenderal Bimbingan Masyarakat Islam, 2007.

Djunaidi, Achmad dan Asyhar, al, Thobieb, Menuju Era Wakaf Produktif (Sebuah Upaya Progresif Untuk Kesejahteraan Umat), Jakarta : Mitra Abadi Press, 2006, Cet ke-3. 
Kabisi, al, Muhammad Abid Abdullah, Hukum Wakaf, Penerjemah Ahrul Sani Faturrahman, dkk, ed, Jakarta : Dompet Dhuafa Republika dan IIMaN, 2004.

Mubarak, Jaih, Wakaf Produktif, Bandung : Simbiosa Rekatama Media, 2008, cet ke-1 September 2008.

Mughniyah, Zawad Muhammad, Fiqih 5 Mazhab, Jakarta : Lentera 1996, cet ke-1.

Mujamil, Qamar, Pesantren dari Transformasi Metodologi Menuju Demokratisasi Institusi, Penerbit Erlangga.

Sofa, Pakde, Pengertian dan Faktor-faktor yang Mempengaruhi Produktivitas Kerja, pada 2 April 2008 dari http//massofa.wordpress.com/2008/04/02/pengertian-dan-faktorfaktor-yang-mempengaruhi-produktifitas-kerja.htm.

Sukiro, Sadono, Pengantar Teori Mikro Ekonomi, Jakarta : PT Raja Grafindo Persada, 1997, cet ke-7.

Tim LP3ES, Profil Pesantren, Jakarta : LP3ES, 1975.

Usman, Suparman, Hukum Perwakafan di Indonesia, Jakarta : Dârul Ulum Press 1999, cet ke-2.

Wawancara pribadi dengan Ibu lin (Bagian keuangan),

Wawancara pribadi dengan Bapak H. Abdul Haris Qodir (Sekretaris Yayasan). 